\title{
Sistem Pakar untuk Pemilihan Program Studi pada Perguruan Tinggi Berbasis Web
}

\author{
Muliansani \\ STKIP Taman Siswa Bima \\ muliansani@gmail.com
}

\begin{abstract}
ABSTRAK
Teknologi sistem informasi saat ini telah dapat berperan sebagai pemberi keputusan. Penerapannyapun telah dipergunakan disegala bidang. Hal tersebut telah mampu membantu manusia dalam menganalisa dalam menentukan pilihan yang tepat dalam mencari jalan keluar dari suatu pemasalahan. Dalam bidang pendidikan, salah satu masalah yang dapat membutuhkan konsultasi atau analisis kepakaran dalam menentukan pilihan dapat dijumpai pada kasus pemilihan studi lanjut yang tepat untuk para siswa yang ingin melanjutkan studi di perguruan tinggi. Berfokus pada masalah tersebut maka tujuan dari penelitian ini adalah untuk mengembangkan aplikasi sistem pakar yang dapat memberikan rekomendasi berupa gambaran bagi siswa mengenai program studi yang sesuai dengan karakter yang dimiliki oleh siswa tersebut. Sistem pakar dikembangan dengan menggunakan pemrograman web dengan tujuan agar aplikasi yang dikembangkan dapat digunakan oleh pengguna secara luas dan realtime. Tahapan penelitian ini menggunakan model Waterfall karena karena sesuai dengan metode yang biasa digunakan dalam pengembangan rekayasa perangkat lunak pada umumnya. Dari hasil penelitian yang dilakukan diperoleh hasil bahwa produk yang dihasilkan berupa aplikasi yang dapat berfungsi sebagaimana tujuan penelitian. Dari hasil testing dan verifikasi akhir menunjukan bahwa aplikasi ini dapat membantu siswa menentukan pilihan program studi yang tepat sesuai dengan karakter dan minat dasar yang dimiliki.
\end{abstract}

Kata Kunci: Sistem Pakar, Program Studi, Web.

\section{PENDAHULUAN}

Dewasa ini penggunaan teknologi informasi memiliki peranan penting sebagai media penghubung yang bersifat global. Beraneka ragam tipe sistem informasi sebagai sarana informasi juga ditandai dengan berkembangnya media penyedia teknologi informasi. Teknologi sistem informasi saat ini juga telah dipergunakan sebagai alat untuk menganalisis yang memiliki kemampuan Identify yaitu mengidentifikasi masalah, Understand yaitu memahami kerja dari sistem yang ada, Analyze yaitu menganalisis sistem, Report yaitu membuat laporan hasil analisis (Jogiyanto, 2001).

Perkembangan teknologi informasi juga didukung oleh adanya teknologi internet yang pada awalnya dianggap sebagai kebutuhan sekunder, kini telah menjadi teknologi yang sangat dibutuhkan oleh banyak kalangan. Penggunaan teknologi internet juga pasti akan dapat memberikan sebuah informasi yang bersifat global dan dapat diakses oleh semua lapisan masyarakat dimanapun dan kapanpun (Nugroho, 2004).

Teknologi internet dalam penyampaian informasinya menggunakan suatu media perangkat lunak (software) yang sering kita sebut website (Bunafit Nugroho, 2004). Website dijadikan salah satu cara penyampaian informasi yang tidak terbatas. Dimana dengan mengakases URL yaitu suatu sarana yang digunakan untuk menentukan lokasi informasi pada suatu web server, sehingga pengguna dapat memperoleh informasi dari layanan internet (Sutarman, 2003)

Dalam hal ini peranan internet telah marambah dunia pendidikan dengan memberikan informasi yang berkaitan dengan dunia pendidikan. Setiap tahunnya perguruanperguruan tinggi dalam negeri akan membuka pendaftaran bagi para calon mahasiswa yang sebagian besar berasal dari lulusan Sekolah Menengah Atas (SMA) dan sederajat. Hal ini menjadikan perguruan tinggi yang mempunyai kualitas baguslah yang akan diminati para calon 
mahasiswa. Dengan banyaknya program studi yang terdapat di perguruan tinggi, maka dengan sendirinya para calon mahasiswa akan dihadapkan dengan beberapa pilihan program studi yang disediakan oleh perguruan tinggi. Secara tidak langsung maka akan timbul suatu pertanyaan yaitu "Program studi apakah yang tepat bagi tiap-tiap calon mahasiswa?". Pertanyaan tersebut muncul karena kurangnya pengetahuan tentang segala sesuatu menyangkut fakultas atau program studi yang ada di perguruan tinggi. Kebanyakan para calon mahasiswa tidak memiliki cukup informasi mengenai ilmu-ilmu yang akan dipelajari dan peluang kerja apa saja yang prospektif untuk mereka setelah menamatkan kuliah di perguruan tinggi yang bersangkutan. Kurangnya pengetahuan ini mengakibatkan begitu banyak calon mahasiswa yang bingung dan salah memilih program studi sehingga pada akhirnya proses perkuliahan berhenti di tengah jalan karena merasa tidak mampu melaksanakan program-program yang telah diatur dalam perkuliahan dan merasa tidak cocok dengan program studi pilihannya. Dalam hal ini kasus yang akan terjadi adalah mahasiswa tersebut karena berbagai pertimbangan memilih pindah dari program studi satu ke program studi lainnya yang dirasa lebih cocok, bahkan lebih parahnya lagi sebagian terpaksa bertahan meneruskan belajar di progam studi yang terlanjur dipilihnya dan karena merasa terpaksa, semangat belajarpun tidak begitu baik sehingga hasil yang dicapai pun tidak sesuai keinginannya. Atas dasar permasalahan tersebut maka penelitian ini ditujukan untuk menghasilkan produk yang dapat menganalisis berdasarkan minat dan bakat yang dimiliki siswa untuk menentukan jenjang studi yang akan dipilih nantinya saat lanjut di perguruan tinggi.

\section{METODE PENLITIAN}

Tahapan pengembangan pada penelitian ini menggunakan model waterfall yang memiliki tahapan dari analisis kebutuhan, desain, implementasi, verifikasi dan maintenance (Royce, Winston, 1970).

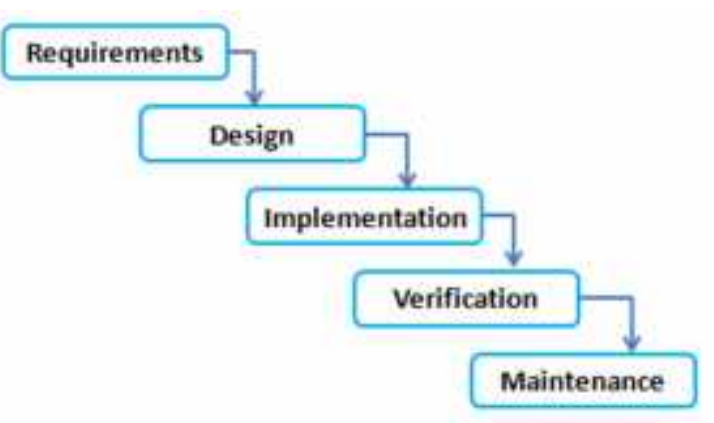

Gambar 1. Model waterfall

\section{Analisi kebutuhan/requirement}

Kebutuhan sistem terdiri dari dua faktor pendukung yaitu kebutuhan perangkat keras (Hardware) dan kebutuhan perangkat lunak (Software), perangkat keras berfungsi sebagai alat pemroses data dan sekaligus digunakan untuk menjalankan aplikasi yang akan dibuat. Adapun itu anatara lain perangkat kerja yaitu kompter dengan spesifikasi khusus programer, server domain dan hosting dan layanan jaringan internet. Perangkat lunak berfungsi untuk membangun sistem informasi yang akan dibuat yaitu PHP, HTML, CSS, Javascript,

\section{Desain}

Pada tahapan ini, sistem dikelompokkan menjadi dua hak akses, yaitu Administrator dan Pengunjung website. Masing-masing mempunyai hak dan kewajiban.

Administrator mempunyai hak dan tanggung jawab sebagai berikut: 1) Dapat mengubah atau mengelola password admin; 2) Dapat mengubah atau mengelola informasi Program Studi dan Fakultas; 3) Dapat mengubah soal-soal pada sistem panduan pemilihan Program Studi; 4) Dapat mengelola Peserta.

Pengunjung website mempunyai hak dan tanggung jawab sebagai berikut: 1) Menjawab soal-soal dari sistem pemilihan Program Studi yang telah disediakan dan mengetahui hasil panduan pemilihan Program Studi; 2) Mendapat informasi tentang Program Studi terpilih; 3) Dapat mencari informasi Program Studi lain yang dikehendaki.

Database yang digunakan dalam pengemabangan sistem ini menggunakan MySQL. Berikut merupakan informasi database yang digunakan pada tahap testing sistem.

Nama host : localhost

Nama database : db_pakar 


\section{Nama user : root}

Untuk desain perancangan alur data dan relasi tabel dapat dilihat pada gambar berikut:

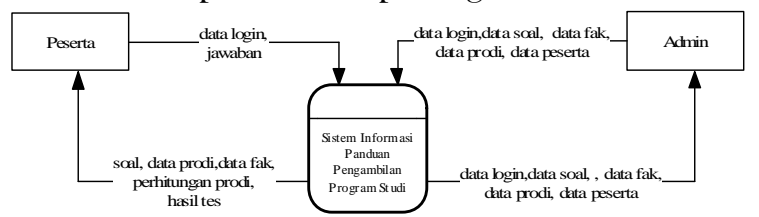

Gambar 2. Diagram Konteks

Peserta akan diberi beberapa pertanyaan yang digunkaan untuk menganalisa minat dan bakat yang dimiliki peserta oleh sistem. Detail alur data digambarkan menggunakan DAD karena dapat menggambarkan sistem dari level yang paling tinggi kemudian menguraikannya menjadi level yang lebih rendah (dekomposisi) (Prasetyo, 2003). Adapun gambarnya sebagai berikut:

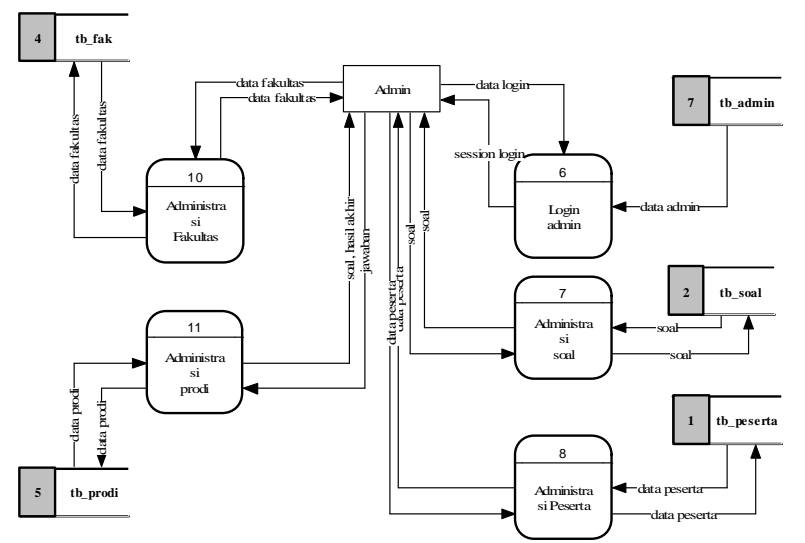

Gambar 3. DAD Admin

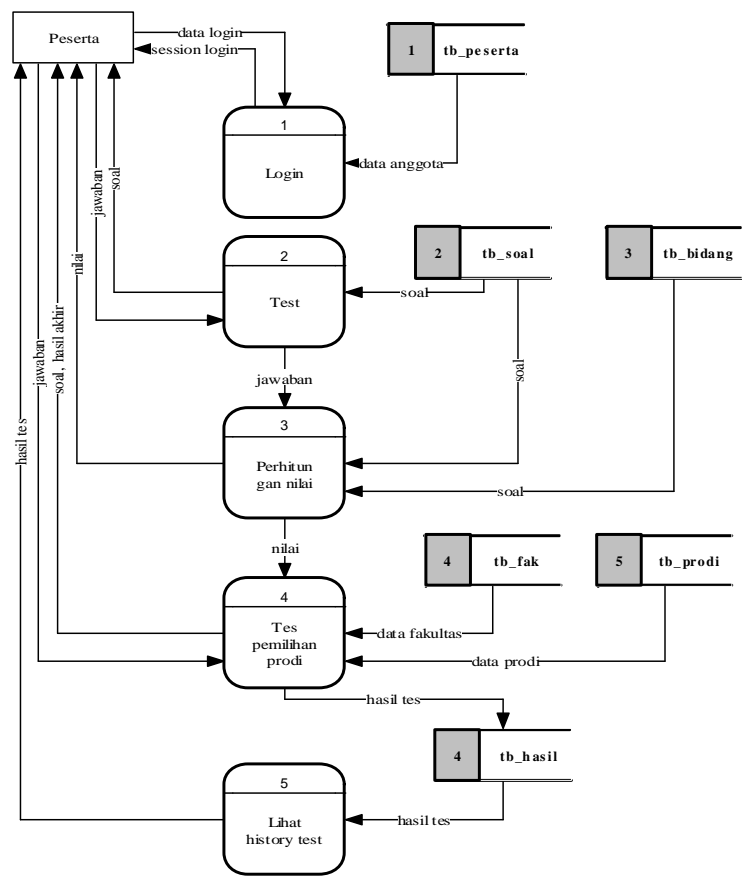

Gambar 4. DAD Peserta
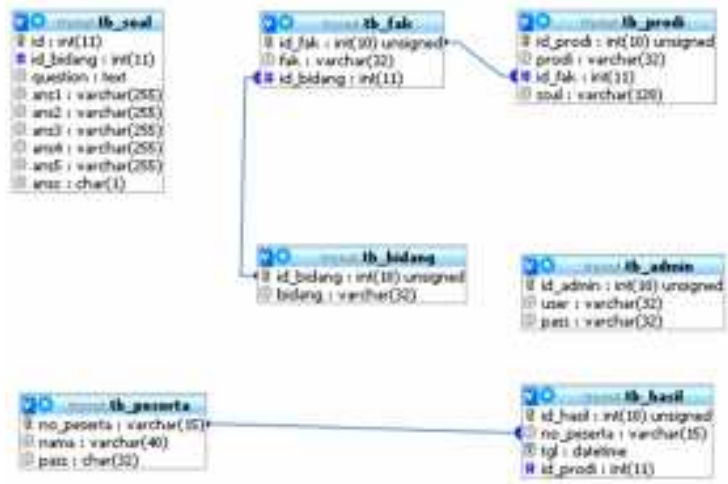

Gambar 5. Relasi Antar Tabel

\section{Implementasi}

Untuk dapat mengakses sistem informasi ini, pengguna harus melakukan pendaftaran terlebih dahulu dengan masuk halaman Sign Up. Setelah proses pendaftaran berhasil maka pengguna dapat melakukan login pada halaman Login. Setelah login, maka pengguna dapat mengakses halaman Test yang berisi soal-soal mata pelajaran umum. Setelah pengguna menjawab soal-soal, maka muncul hasil skor dari soal-soal yang telah dijawab berupa skor soal Eksakta dan Non Eksakta. Setiap hasil Eksakta Maupun Non Eksakta mempunyai soal-soal tersendiri yang akan muncul kemudian. Pengguna harus menjawab soal tersebut untuk mengetahui hasil akhir minat pengguna akan Program studi yang dipilihnya. Kemudian hasil akhir berupa Program Studi terpilih akan muncul saat pengguna masuk halaman History.

\section{Verifikasi}

Dari tahapan proses coding dan desain layout yang dilakukan maka dilakukan testing terhadap aplikasi yang dikembangkan. Hasilnya menunjukan bahwa aplikasi berjalan normal dengan sedikit perubahan pada segi tampilan namun tidak merubah pada rancangan sistem. Testing ini dilakukan agar aplikasi dapat digunakan dengan mudah.

\section{HASIL PENELITIAN}

Setelah dilakukan testing dan verifikasi, diperoleh hasil yang menyatakan produk yang dikembangkan layak untuk diterapkan dan diimplemtasikan sesuai dengan fungsi dan tujuannya. Adapun tampilan dari hasil perancangan: 


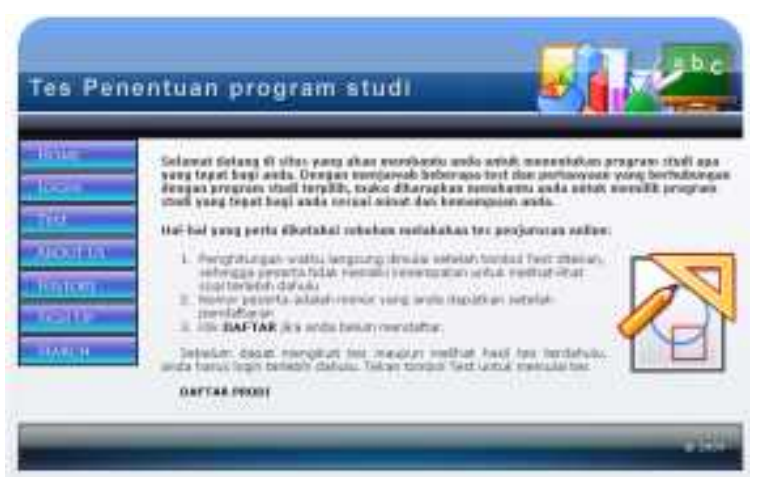

Gambar 6. Halaman Utama

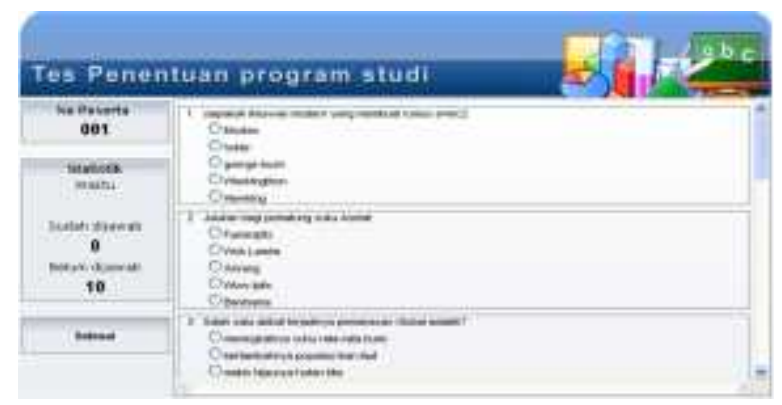

Gambar 7. Test

Setelah test maka muncul skor Eksakta dan Non Eksakta yang akan menampilkan pilihanpilihan untuk pemilihan program studi yang diminati

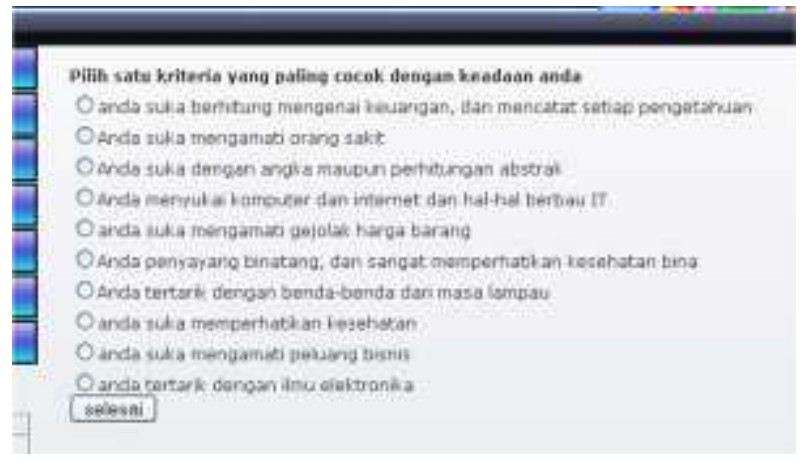

Gambar 8. Soal pemilihan prodi

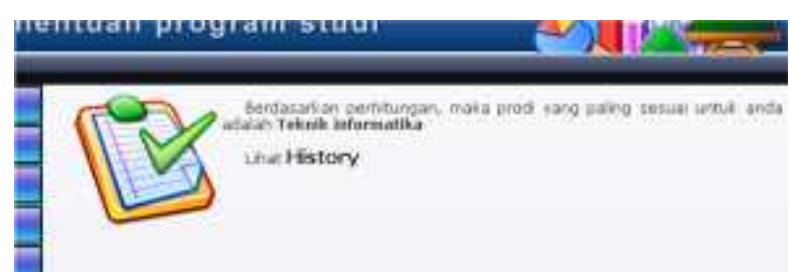

Gambar 9. Hasil pemilihan soal prodi

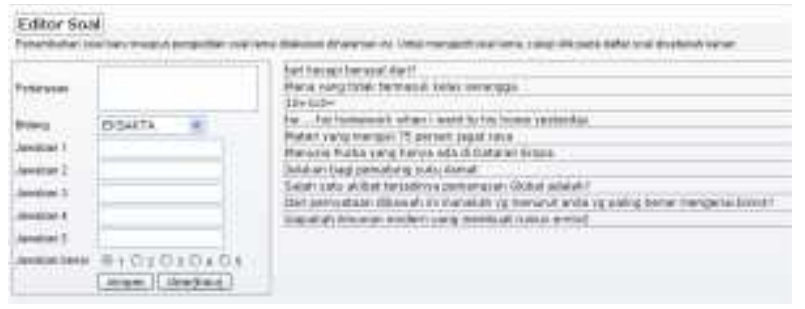

Gambar 10. Halaman kelola soal

\section{KESIMPULAN}

Dari hasil penelitian yang dilakukan maka dapat dikemukakan bahwa penelitian yang dilakukan telah menghasilkan satu set sistem informasi panduan pemilihan program studi, informasi yang ditampilkan adalah suatu rekomendasi pemilihan program studi melalui tanya jawab bakat dan minat yang memberikan gambaran kepada pengguna website, sehingga pengguna dapat menentukan program studi yang tepat; Sistem informasi ini dapat membantu memberikan informasi tentang program studi yang ada di perguruan tinggi pada umumnya. Dengan demikian, hasil penelitian ini telah dapat memberikan kontribusi positif bagi masyarakat khusunya bagi siswa yang masih belum dapat menentukan pilihan program studi apa yang tepat untuk studi lanjutnya nanti.

\section{DAFTAR PUSTAKA}

Andri Pranolo, 2006. "Analisa dan Implementasi Website E-Learning Berbasis Web dan MySql (Studi Kasus LABLINKESHUT Fakultas Kehutanan UGM)". Yogyakarta.

Bunafit Nugroho, 2004, Aplikasi Pemrograman

Dinamis dengan PHP dan Mysql, Gava Media, Yogyakarta.

Jogianto, HM, 1990, Analisa dan Desain Sistem Informasi: Pendekatan Terstruktur Teori dan Praktek Aplikasi Bisnis, Andi Offset, Yogyakarta.

Royce, Winston (1970), "Managing the Development of Large Software Systems" (PDF), Proceedings of IEEE WESCON, 26 (August): 1-9

Stanilaus Sulismoko, 2002. "Sistem E-Learning Berbasis Web Untuk Mendukung Perkuliahan". Yogyakarta.

Supriyatno, 2008. "Implementasi Sistem Informasi Dosen Dan Materi Kuliah Online Berbasis Web. UTY Yogyakarta"

Sutarman, 2003, Membangun Aplikasi Web dengan PHP dan MySQL, Graha Ilmu, Yogyakarta. 